Gut, 1971, 12, 437-441

\title{
Absorption studies in patients with 'intraabdominal ileostomy reservoirs' and in patients with conventional ileostomies
}

\author{
R. JAGENBURG, G. DOTEVALL, J. KEWENTER, N. G. KOCK, AND B. PHILIPSON \\ From Surgical Department III, the Department of Clinical Chemistry, and Medical Department II, Sahlgren's \\ Hospital, University of Gothenburg, Gothenburg, Sweden
}

SUMmARY Twenty patients with ileostomy were studied concerning the absorption of D-xylose, fat, L-phenylalanine, and vitamin $B_{12}$. Ten patients had a conventional ileostomy, whereas 10 others were provided with an intraabdominal intestinal ileostomy reservoir resulting in faecal continence.

No remarkable differences in the absorption of D-xylose, fat, or L-phenylalanine were found between the two groups of ileostomy patients. Most of the absorption values were within normal or borderline ranges. In the reservoir group the Schilling test gave subnormal values in six out of 10 patients, whereas only one patient in the group with a conventional ileostomy had a subnormal value. The reason for this finding is briefly discussed.

The progressive decline in mortality and morbidity associated with proctocolectomy, together with the good results after present-day surgical treatment of patients with colitis, has led to a wider use of proctocolectomy both in patients with mucous ulcerative colitis and transmural regional enteritis localized to the colon. Consequently the number of patients provided with a permanent ileostomy continues to increase. Although most of these patients are restored to normal health and active and productive lives the ileostomy creates in many of them social and psychological problems. The flow of intestinal contents through the ileostomy is more or less continuous and not voluntarily controlled except to a small extent by the diet. Ileostomy appliances have to be carried continuously in order to collect the intestinal discharge. The possibility of leakage is always present and odour from the intestinal discharge constitutes a serious problem for some patients. Occasional or constant skin irritation is a frequent late complication of ileostomy (Watts, de Dombal, and Goligher, 1966; Biermann, Tocker, and Tocker, 1966).

In order to eliminate these drawbacks of the ileostomy an intraabdominal ileal reservoir was constructed in patients with permanent ileostomy (Kock, 1969). In most of the patients faecal continence was obtained and external ileostomy Received for publication 29 December 1970. appliances became unnecessary (Kock, 1970, 1971). The patients empty the reservoir two or three times a day with the aid of a catheter. As the intestinal contents are stored longer in the intestine of the patients with an ileostomy reservoir than in patients with a conventional ileostomy it was theoretically possible that absorption could be improved by the ileostomy reservoir. On the other hand changes in the ileal microbial flora of the reservoir (Brandberg, Kock, and Philipson, 1971) and possible structural changes in the mucous membrane of the reservoir could affect the absorptive capacity of this part of the intestine resulting in decreased absorption.

The aim of the present investigation was to elucidate these problems by comparing some absorption parameters in patients with ileostomy reservoirs with those in patients with conventional ileostomies.

\section{Material and Methods}

Twenty patients who had previously undergone proctocolectomy were studied. In 10 patients an intraabdominal intestinal reservoir had been connected to the ileostomy (Kock, 1969) whereas the other patients had conventional ileostomies. The indications for the operations were mucous ulcerative colitis, transmural reginal enteritis, and familial polyposis (Table I). In none of the patients with 


\begin{tabular}{lll}
\hline & Ileostomy & Reservoir \\
\hline Ulcerative colitis & 6 & 8 \\
Crohn's disease & 3 & 2 \\
Familial polyposis & 1 & \\
\hline
\end{tabular}

Table I Indications for proctocolectomy in 10 patients with conventional ileostomy and in 10 patients with ileostomy reservoir

\begin{tabular}{lll}
\hline Age Group (years) & $\begin{array}{c}\text { Conventional } \\
\text { Ileostomy }\end{array}$ & $\begin{array}{l}\text { Ileostomy } \\
\text { Reservoir }\end{array}$ \\
\hline $10-20$ & 1 & - \\
$20-30$ & - & 3 \\
$30-40$ & 3 & 1 \\
$40-50$ & 3 & 4 \\
$50-60$ & 3 & 2 \\
& 10 & 10 \\
\hline
\end{tabular}

Table II The age distribution of the patients in the two groups studied

Crohn's disease was the small intestine involved. The age distribution of the patients in the two groups is given in Table II. The patients with conventional ileostomy had undergone the operation one to 10 years before the investigation, whereas the patients with ileostomy reservoir had been operated on less than two years before the study. The patients were all in good general health and well rehabilitated. They were admitted to hospital during the study.

Before the absorption tests were carried out blood samples were taken for determination of haemoglobin, serum iron, total iron-binding capacity (TIBC), serum folate, serum vitamin $B_{12}$, electrolytes, and serum creatinine.

\section{D-XYLOSE EXCRETION TEST}

D-xylose, $25 \mathrm{~g}$, in $500 \mathrm{ml}$ water was administered to the fasting patients and urine was collected for five hours. Urinary D-xylose was determined according to a modification (Kerstell, 1961) of the method of Roe and Rice (1948). Urinary excretion $\geq 5 \mathrm{~g} / 5$ hours is considered as normal.

FAT BALANCE

The patients were kept on a standard diet containing $100 \mathrm{~g}$ fat daily for six days. The contents from the ileostomy reservoir and the output from the conventional ileostomy were collected in one-day periods. Carmine as a marker for the collection was given before, in the middle, and at the end of the study. The collections were weighed and the fat content of each collection was determined according to the method of van de Kamer, ten Bokkel Huinik, and Weyers (1949). A mean faecal excretion of less than $6 \mathrm{~g}$ /day is considered as normal.

\section{PHENYLALANINE ABSORPTION TEST}

The patients were given $100 \mathrm{mg} \mathrm{L}$-phenylalanine per $\mathrm{kg}$ body weight dissolved in $300 \mathrm{ml}$ of coffee. The loading was performed in the morning with the patient in the fasting state. Venous blood was taken before and 30, 45, 60, 90, 120, and $180 \mathrm{~min}$ after the loading. Plasma phenylalanine was measured fluorimetrically (Wong, O'Flynn, and Inouye, 1964).

\section{SCHILLING TEST}

It was carried out as described by Gräsbeck, Nyberg, and Siurala (1956). Urinary excretion exceeding $10 \%$ was considered as normal. The test was done without administration of intrinsic factor. None of the patients had anacidity as revealed from a normal gastric secretion test (Diagnex-blue).

\section{VITAMIN B 12}

Vitimin $\mathbf{B}_{12}$ in serum was determined by a microbiological method (Hutner, Bach, and Ross, 1956) using Euglena gracilis (Z-strain). Vitamin $\mathrm{B}_{12}>150$ $\mathrm{ng} / \mathrm{l}$ is regarded as normal.

\section{FOLATE}

Folate in serum was assayed with Lactobacillus case $i$ according to the technique described by Hansen (1964). Values of serum folate $\geq 3.0 \mathrm{ng} / \mathrm{ml}$ are regarded as normal.

\section{Results}

The levels of haemoglobin, serum iron, TIBC, and serum folate were normal in all cases and there were no significant differences between the two groups. Serum creatinine and electrolytes were also normal in all instances. The urinary $\mathrm{D}$-xylose excretion was less than $5 \mathrm{~g} /$ five hours in four out of 10 patients with conventional ileostomy and in five out of 10 patients with reservoir (Fig. 1). The subnormal values were not correlated to the time lapse after operation nor to the primary disease for which the operation was performed.

The fat excretion exceeded $6 \mathrm{~g} / 24$ hours in four out of 10 patients in the ileostomy group and in eight out of 10 in the reservoir group but the mean excretion in the two groups was similar (7.6 and $8.3 \mathrm{~g}$ respectively). The highest fat excretion observed was $14 \mathrm{~g} / 24$ hours. The mean weight of the intestinal discharge was $558 \mathrm{~g} / 24$ hours for patients with ileostomy and $642 \mathrm{~g} / 24$ hours for patients with reservoir (Fig. 2).

The phenylalanine absorption as shown by the plasma phenylalanine curve after oral loading was similar in the two groups (Fig. 3) and did not differ from that obtained in normal subjects (Jagenburg and Rödjer, 1971). The mean body weight was 


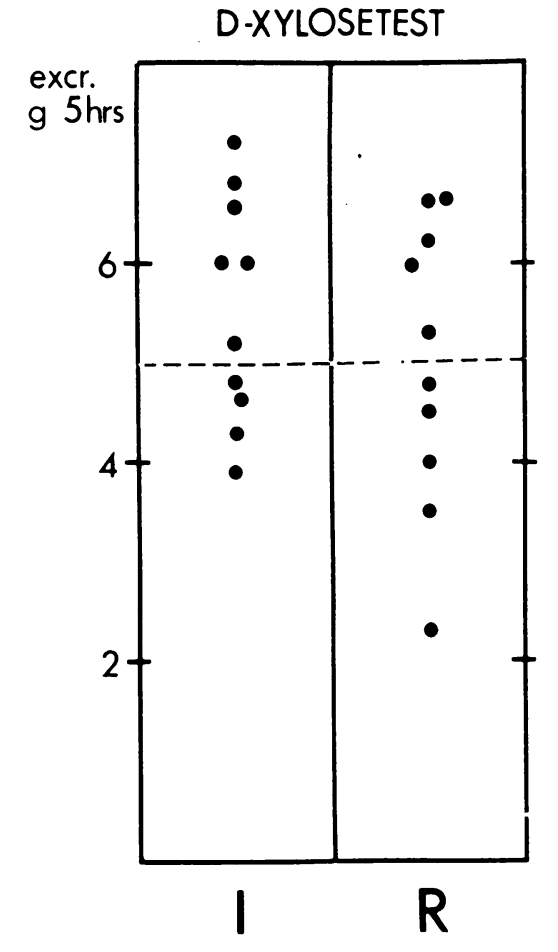

Fig. 1 D-xylose excretion (normal $>5$ g/five hours) in 10 patients with conventional ileostomy $(I)$ and in 10 patients with ileostomy reservoir $(R)$.

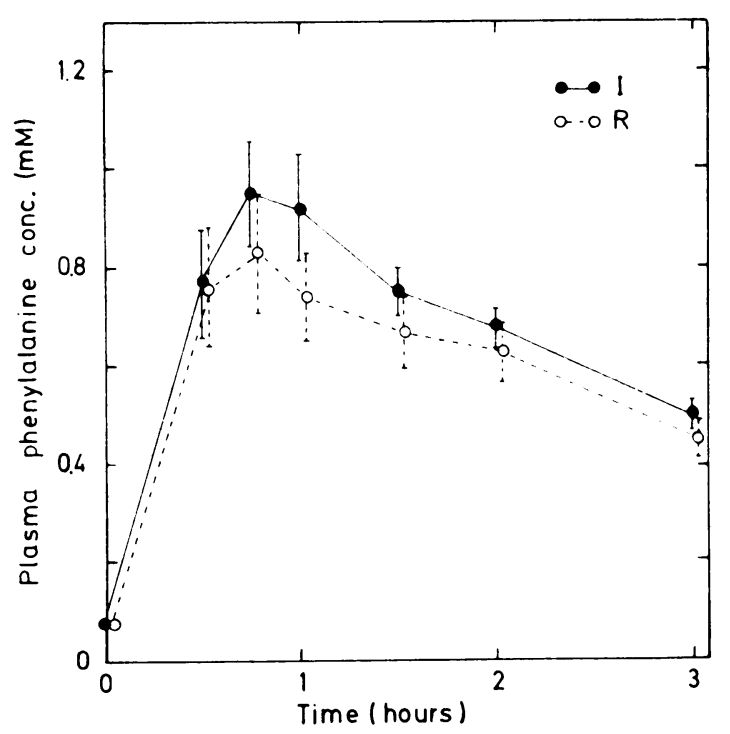

Fig. 3 Plasma phenylalanine curve after oral L-phenylalanine loading ( $50 \mathrm{mg} / \mathrm{kg}$ body weight) in 10 patients with conventional ileostomy (-_ ) and 10 patients with ileostomy reservoir (0- . - - - o). The means and $S E$ are given. 


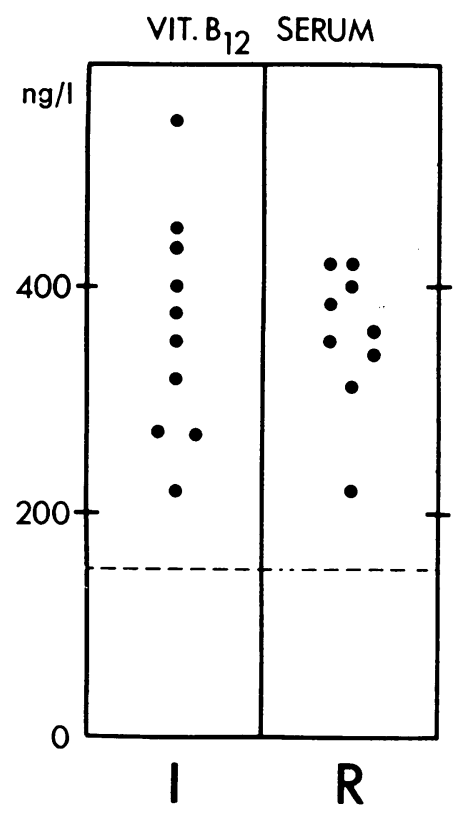

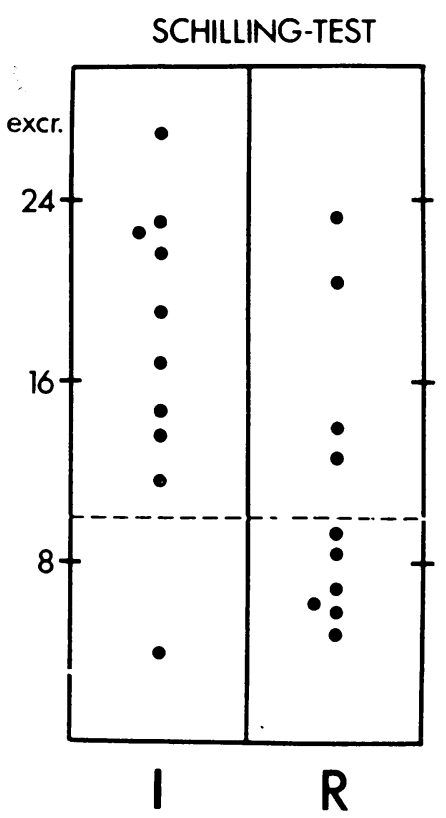

Fig. 4 Vitamin $B_{12}$ level in serum (normal > $150 \mathrm{ng} / \mathrm{l}$ ) and the results from Schilling test (normal $>10 \%$ ) in 10 patients with conventional ileostomy $(I)$ and 10 patients with ileostomy reservoir $(R)$. somewhat higher in the ileostomy group $(68.2 \mathrm{~kg})$ than in the reservoir group $(57.9 \mathrm{~kg})$. This explains the slightly higher plasma phenylalanine concentrations in the ileostomy group (Jagenburg and Rödjer, 1971), as the test dose of phenylalanine was given in relation to body weight.

Vitamin $\mathbf{B}_{12}$ in serum was within the normal range in all patients.

The Schilling test was below $10 \%$ only in one of the patients with a conventional ileostomy but in six out of 10 patients with a reservoir (Fig. 4).

\section{Discussion}

It is remarkable that the complete removal of the colon and rectum in man does not produce serious absorptive and metabolic disturbances. Although proctocolectomy and ileostomy have been more widely used only during the last two decades it is well documented that the majority of these patients are restored to excellent health and good rehabilitation (Roy, Sauer, Beahrs, and Farrow, 1970). Except for a loss of bicarbonate and water in the alkaline ileostomy effluent, resulting in slight dehydration and increased urine acidity in some ileostomy patients (Clarke and McKenzie, 1969), the absorption seems to be unaffected by the proctocolectomy as judged from long-term observations of these patients.
In the present series of 10 patients with conventional ileostomy four had slightly reduced $D$-xylose absorption (4-5 $\mathrm{g}$ xylose excreted in the urine per five hours), four had a somewhat reduced fat absorption $(85-90 \%)$, and one had a low Schilling test (excretion $4 \%$ ). The subnormal values were not correlated to the time lapse since the operation nor to the disease causing the operation. From the present investigation it appears that a slightly impaired absorption of $D$-xylose, fat, and vitamin $\mathbf{B}_{\mathbf{1 2}}$ may occur in patients with ileostomy. Because of the excellent health of the patients with subnormal values the clinical significance of the slightly impaired absorption can, however, be questioned.

The introduction of the ileostomy reservoir as part of the armamentarium for the management of patients with a permanent ileostomy raises questions on the influence of this procedure on the absorption of the small intestine. Because of the storage of the intestinal contents in the reservoir improved absorption could be expected. The changed microbial flora in the ileostomy reservoir (Brandberg et al, 1971), on the other hand, could negatively influence the absorption as there might be a bacterial consumption of, for example, carbohydrates.

As seen from the present study there was no significant difference in the absorption of D-xylose, L-phenylalanine, and fat between the patients with conventional ileostomies and those with reservoirs. 
The relatively high faecal fat excretion values in the present investigation require some comment. According to the reports of some authors (Wollaeger, Comfort, and Osterberg, 1947; Skala, Krondl, Vulterinová, Horáčková, and Štastná, 1967), an increase in dietary fat intake leads to an increase in faecal fat loss both in healthy subjects and in patients with malabsorption. Previous studies of faecal fat excretion in patients with ileostomy seems to have been performed with the patients on their usual diet (Kramer, Kearney, and Ingelfinger, 1962) whereas the subjects in our study were kept on a standard diet containing $100 \mathrm{~g}$ fat daily. The relatively high dietary fat content in our study can probably explain the high faecal fat values found in both groups in our study. The faecal weight can be regarded as a crude measure of water absorption. Although the weight varied considerably between individuals the distribution of the weight values was, however, equal in both groups, indicating no significant difference in water absorption.

Vitamin $\mathrm{B}_{12}$ in serum was within the normal range in all patients. The patients in the reservoir group had, however, been operated on less than two years before the investigation and no conclusions can therefore be drawn from these values concerning absorption. Six out of 10 patients with a reservoir had subnormal Schilling test values. One explanation for this remarkable finding could be that, according to Hultén, Kewenter, Persson, and Åhrén (1970), the Schilling test values are often low when determined within one year after the creation of an ileostomy. Most of the patients having had an ileostomy for more than one year had a normal Schilling test. Another possibility could be that the absorptive capacity of the terminal ileum, used for construction of the reservoir, is diminished either because of the bacterial flora or because of structural changes in the mucous membrane. Studies are in progress to elucidate these questions.

This work was supported by the Swedish Medical Research Council (project no. B71-17x-577-07A, B71-13x-652-06A).
References

Biermann, H. J., Tocker, A. M., and Tocker, L. R. (1966). Statistical survey of problems in patients with colostomy or ileostomy. Amer. J. Surg., 112, 647-650.

Brandberg, A., Kock, N. G., and Philipson, B. (1971). The microbial flora of intestinal effluent in patients with conventional ileostomy and in patients with intraabdominal ileostomy reservoir. (To be published.)

Clarke, A. M., and McKenzie, R. G. (1969). lleostomy and the risk of urinary uric acid stones. Lancet, 2, 395-97.

Gräsbeck, R., Nyberg, W., and Siurala, M. (1956). Urinary excretion of radiovitamin $\mathbf{B}_{12}$ (Schilling test). (Swedish.) Nord. Med. 56, 1656-1658.

Hansen, H. A. (1964). On the diagnosis of folic acid deficiency. Academic thesis, Göteborg.

Hultén, L., Kewenter, J., Persson, E., and Åhrén, C. (1970). Vitamin $B_{12}$-absorption in ileostomy patients after operation for ulcerative colitis. Scand. J. Gastroent., 5, 113-116.

Hutner, S. H., Bach, M. K., and Ross, C. I. M., (1956). A sugarcontaining basal medium for vitamin $\mathbf{B}_{12}$-assay with Euglena; application to body fluids. J. Protozool., 3, 101-112.

Jagenburg, R., and Rödjer, S. (1971). To be published.

van de Kamer, J. H., ten Bokkel Huinink, H., and Weyers, H. A. (1949). Rapid method for the determination of fat in feces. J. biol. Chem., 177, 347-355.

Kerstell, J. (1961). A simplified method for the determination of xylose in urine. Scand. J. clin. lab. Invest., 13, 637-641.

Kock, N. G. (1969). Intra-abdominal 'reservoir' in patients with permanent ileostomy. Arch. Surg., 99, 223-231.

Kock, N. G. (1970). Continent ileostomy with the aid of an intraabdominal ileal pouch. 4th World Congress of Gastroenterology, Copenhagen, Denmark, 12th-18th July, 1970. Advance abstracts.

Kock, N. G. (1971). Ileostomy without external appliances. A survey of 25 patients provided with intraabdominal intestinal reservoir. Ann. Surg., in press.

Kramer, P., Kearney, M. M., and Ingelfinger, F. J. (1962). The effect of specific foods and water loading on the ileal excreta of ileostomized human subjects. Gastroenterology, 42, 535-546.

Roe, J. H., and Rice, E. W. (1948). A photometric method for the determination of free pentoses in animal tissues. J. biol. Chem., 173, 507-512.

Roy, P. H., Sauer, W. G., Beahrs, O. H., and Farrow, G. M. (1970). Experience with ileostomies. Evaluation of long term rehabilitation in 497 patients. Amer. J. Surg., 119, 77-86.

Skála, I., Krondl, A., Vulterinová, M., Horácková, J., and Stastná, R. (1967). Effect of increased dietary fat intake in patients after resection of the small intestine and malabsorption of different aetiology on faecal fat excretion. Gastroenterologia (Basel), 108, 297-308.

Watts, J. McK., de Dombal, F. T., and Goligher, J. C. (1966). Longterm complications and prognosis following major surgery for ulcerative colitis. Brit. J. Surg., 53, 1014-1023.

Wollaeger, E. E., Comfort, M. W., and Osterberg, A. E. (1947). Total solids, fat and nitrogen in the feces: III. A study of normal persons taking a test diet containing a moderate amount of fat; comparison with results obtained with normal persons taking a test diet containing a large amount of fat. Gastroenterology, 9, 272-283.

Wong, P. W. K., O'Flynn, M. E., and Inouye, T. (1964). Micromethods for measuring phenylalanine and tyrosine in serum. Clin. Chem., 10, 1098-1104. 